\title{
SUSTAINABLE DEVELOPMENT OF OLD AND HERITAGE CITY-CENTERS AND THE CHALLENGES OF MODERN URBAN DEVELOPMENT ( THE CASE OF OLD ASSIUT CITY CENTER )
}

Esam El-Din Kamal Mahrous, Ass. Prof.

Email: dr_essam_mahrous@yahoo.com ;Tel.0123971272

Mohamed-Ayman Abd-Elmajeed Daef, Ass. Prof.

Email: deaf@aun.edu.eg ; Tel.0101018467

Architectural Engineering Department, Faculty of Engineering, Assuit University, Egypt

(Received July 19, 2006 Accepted August 22, 2006)

Old and heritage city-centres in Egypt represent unique urban entities characterized by historical atmospheres which mostly belong to Arab culture dating to Islamic eras, particularly the Mamloukian period. Singular activities aiming to conserve or restore certain heritage buildings in such areas are usually incapable to achieve the required development objectives. Therefore, adopting a comprehensive sustainable development strategy may represent a proper approach to deal with problems of degradation, and urban and economic deterioration facing old and heritage city-centers. Modern and rapid urban developments in old city-centres have contributed to the loss of cultural and economic values. Therefore, re-use and rehabilitation of such areas in coherence with current social and economic circumstances should be considered as a determining factor in any comprehensive sustainable urban development strategy for the given area. This paper proposes a development programme that comprises many stages: urgent ones aim at preventing rapid deterioration; and consequent stages aim to achieve sustainable development of such important areas of Egyptian cities.

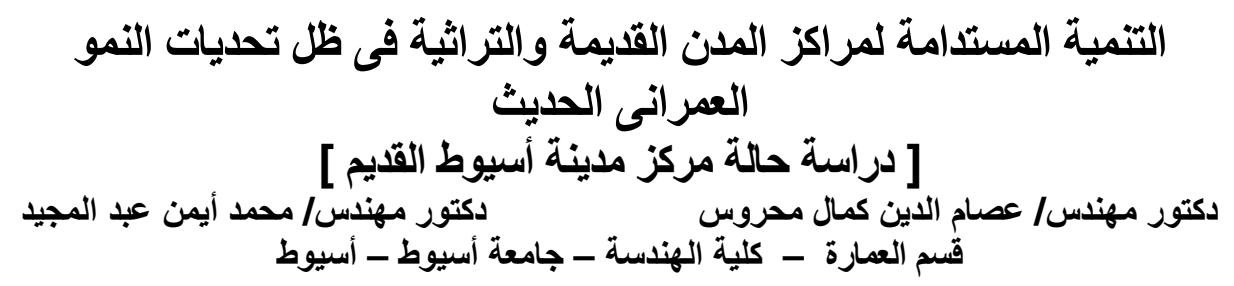

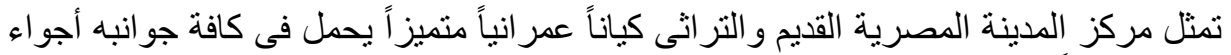

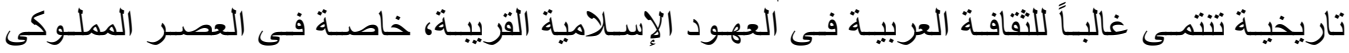
(923/648 هجرية - 1517/1250 ميلادية). العمليات المنفردة للحفاظ أو الترميم لبعض المباني 
التر اثية فى هذه المنطقة لا تحقق أهداف التتمية المطلوبة للمنطقة. ومن ثم فإن تبنى منظومة تنمية شـاملة

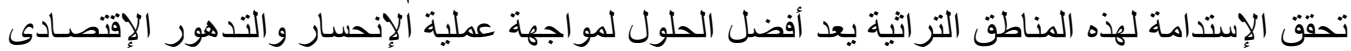

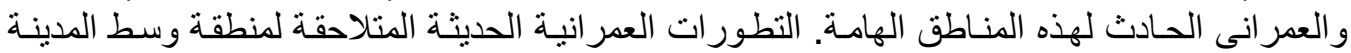

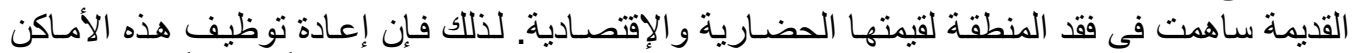

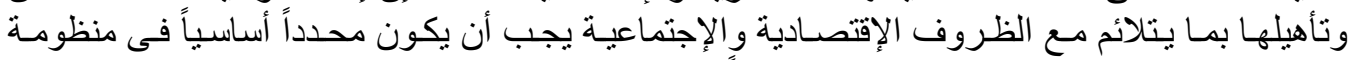

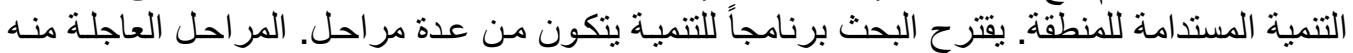

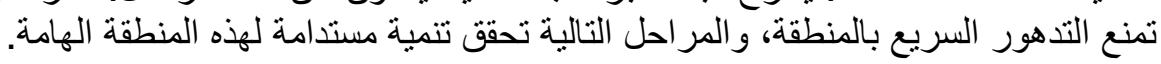

\section{1 - 1 المقدمة المقة}

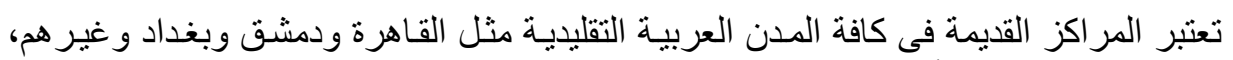

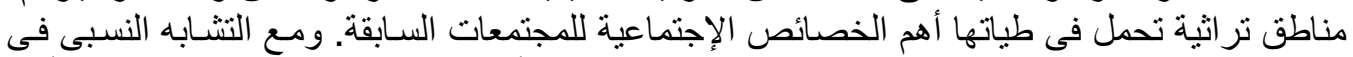

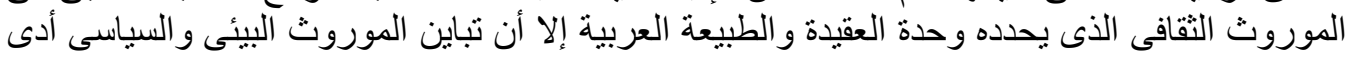

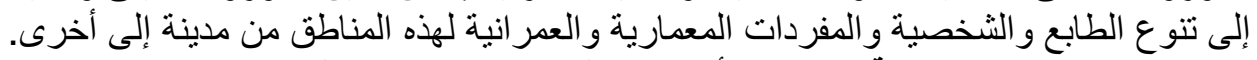

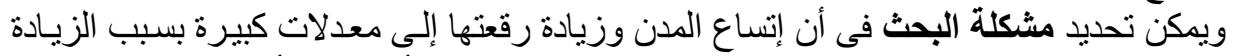

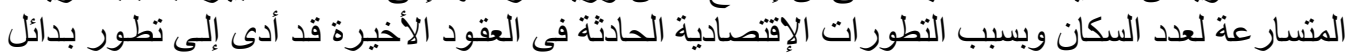

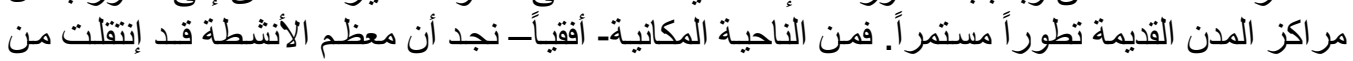

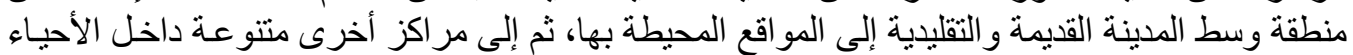

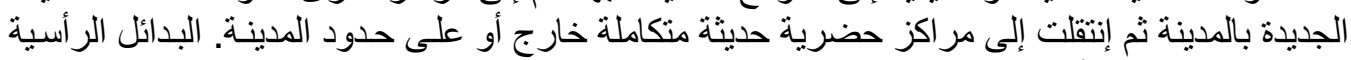

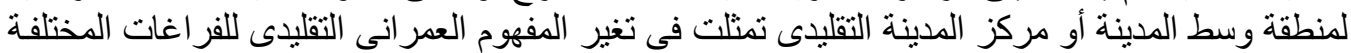

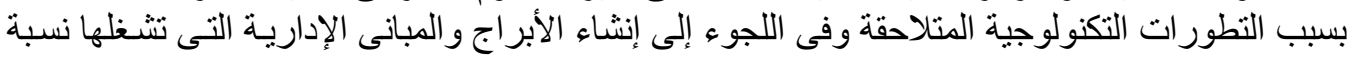

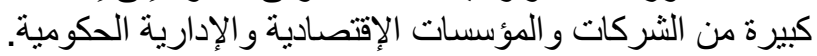

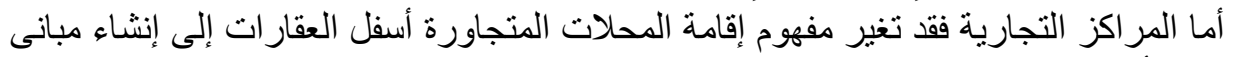

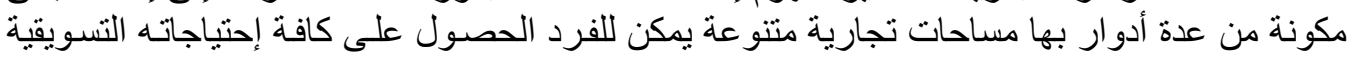

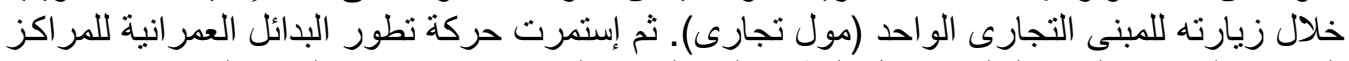

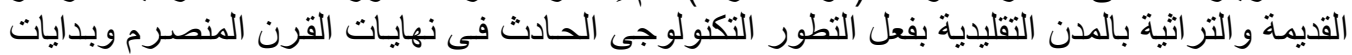

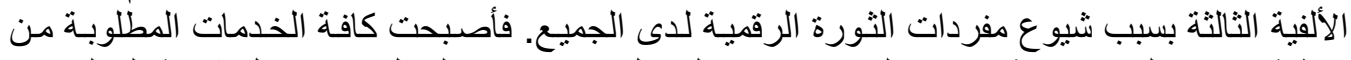

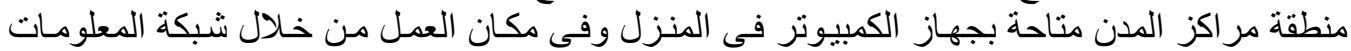

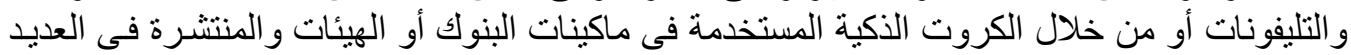

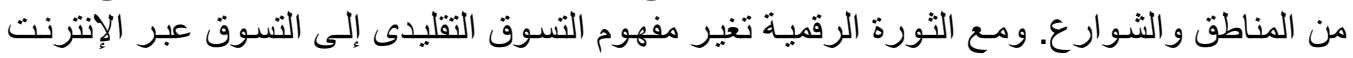

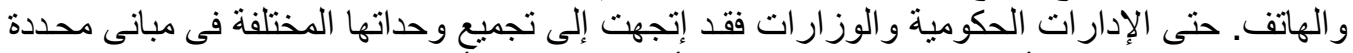

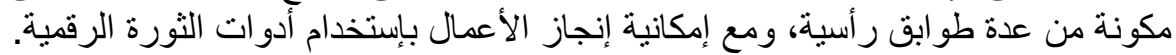

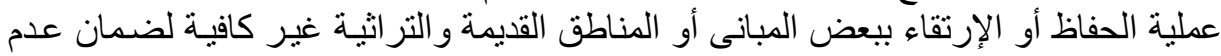

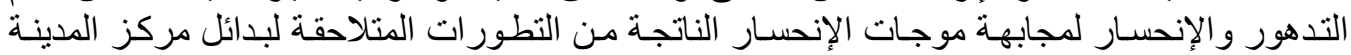

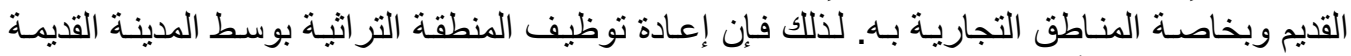

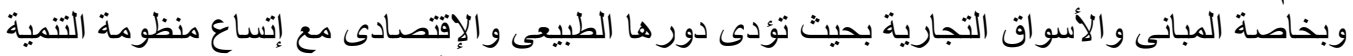

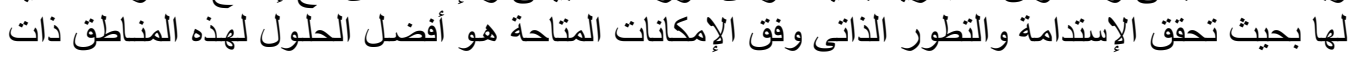

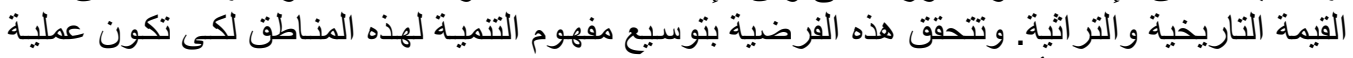

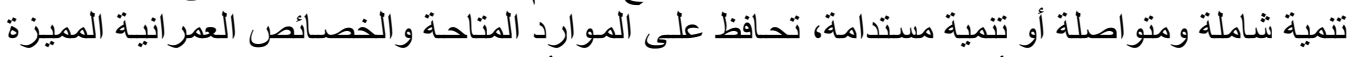

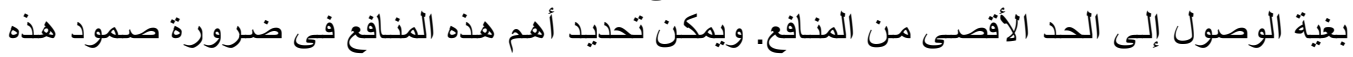

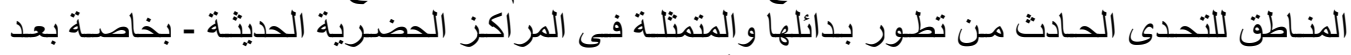

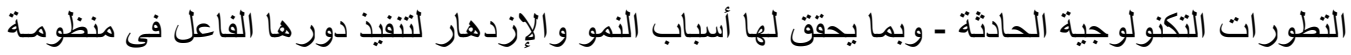
التنمية و التطور للتجتمع و المدينة ككل. 


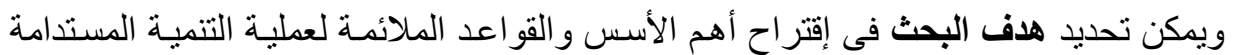
لمركز المدينة القديم و التراثي رغم التطور المستمر للبدائل العمر انية الحديثة لهذه المنطقة.

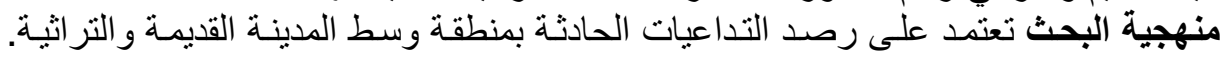

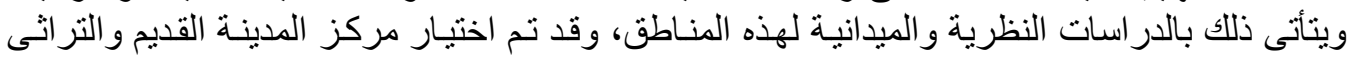

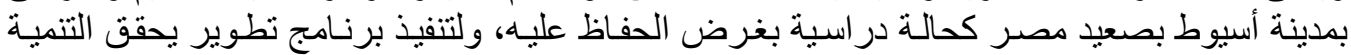

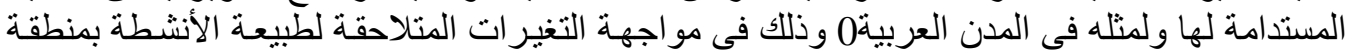

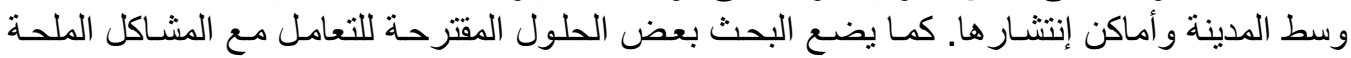
بهذه المناطق التر اثية الهامة.

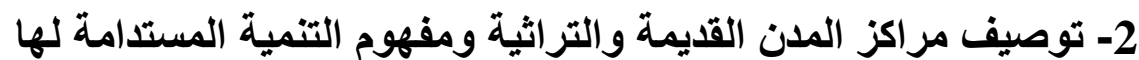

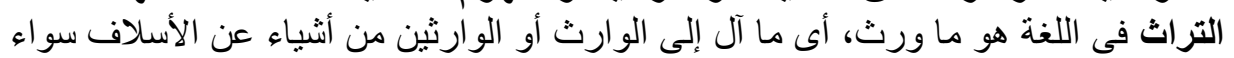

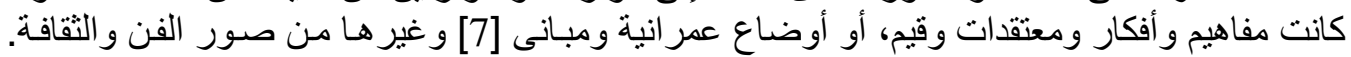

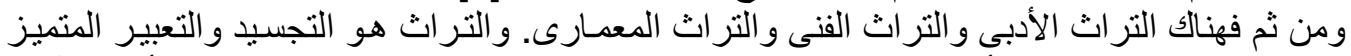

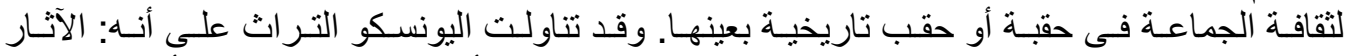

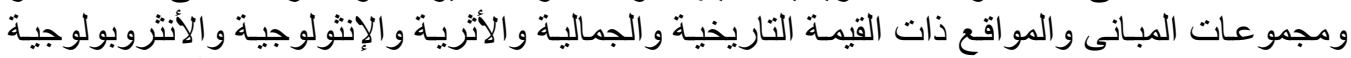

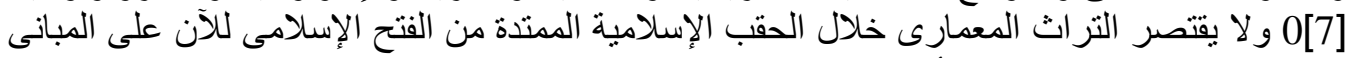

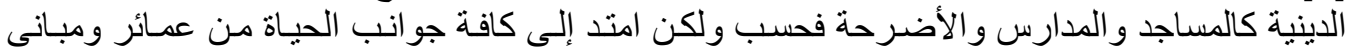

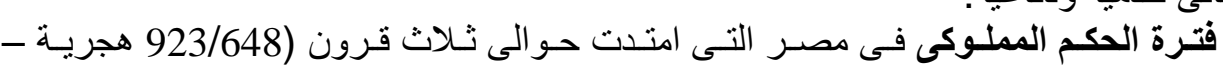
عامة ومبانى خدمية ودفاعية.

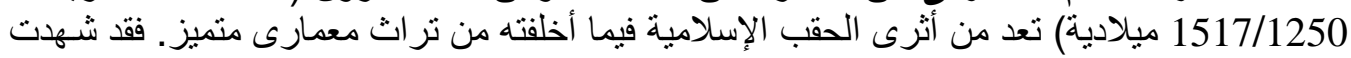

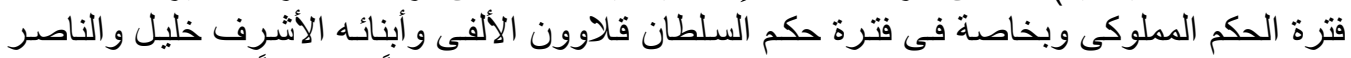

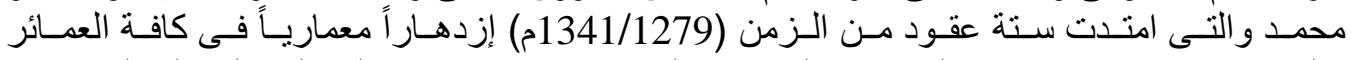

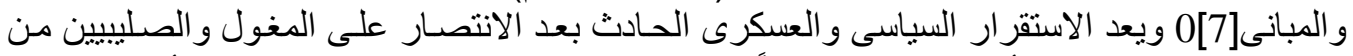

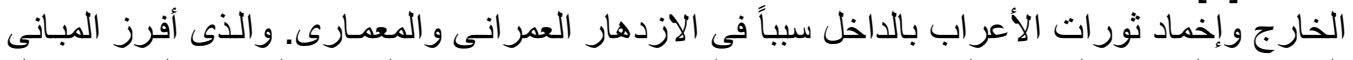

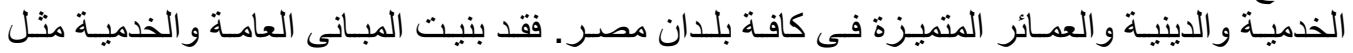

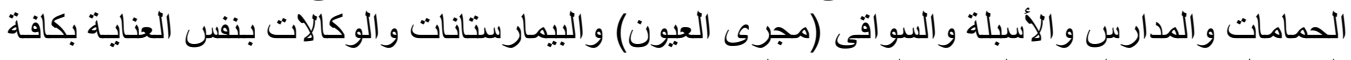

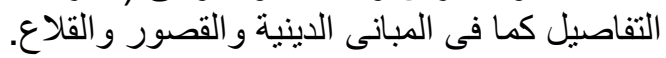

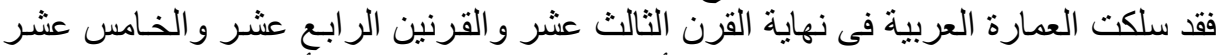

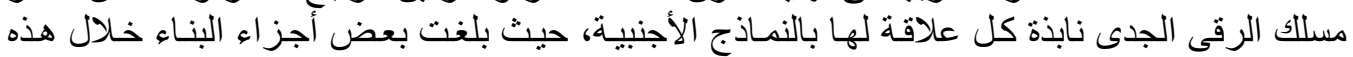

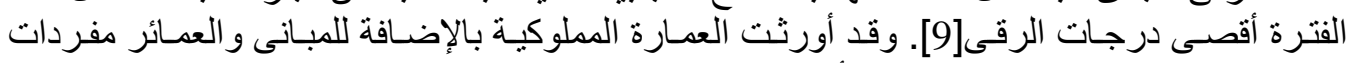

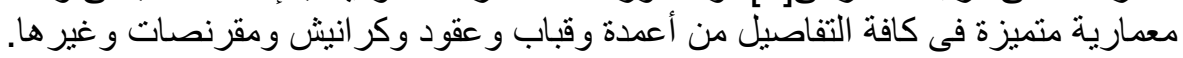

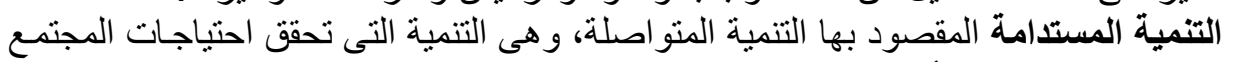

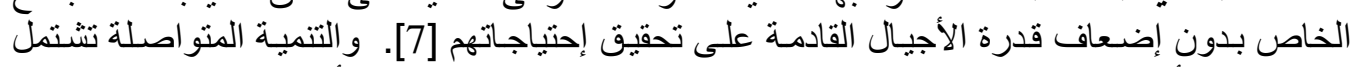

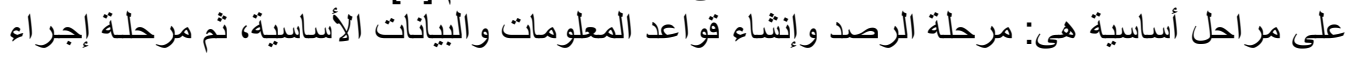

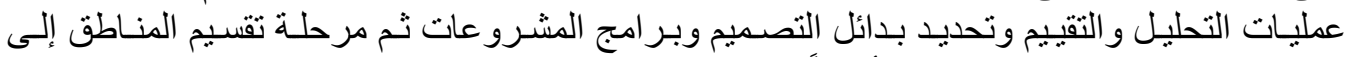

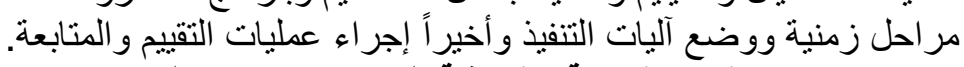

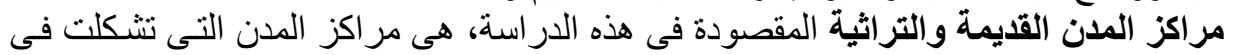

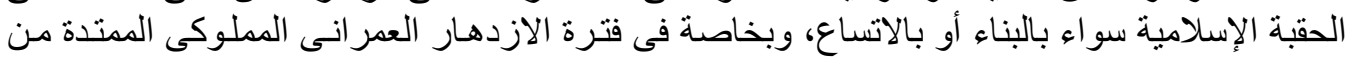

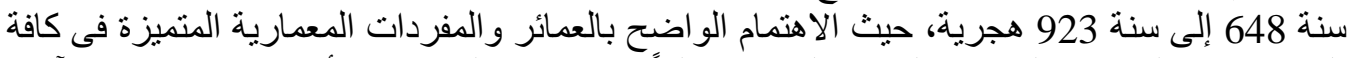

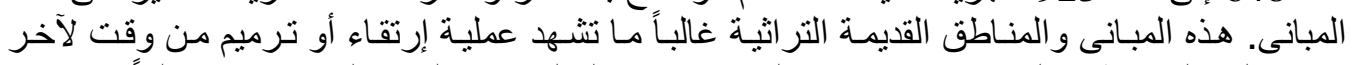

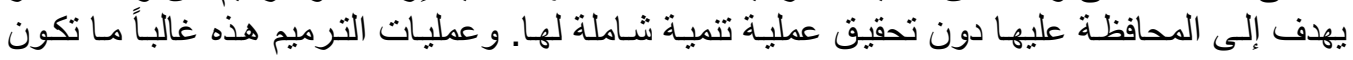
بمعونات تقدمها جهات تمويل دولية. 


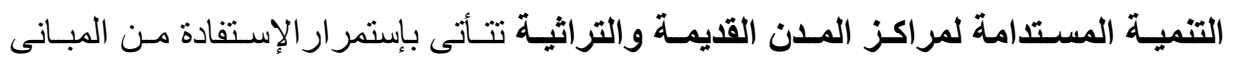

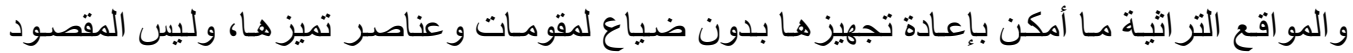

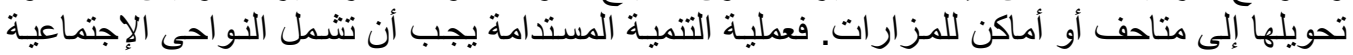

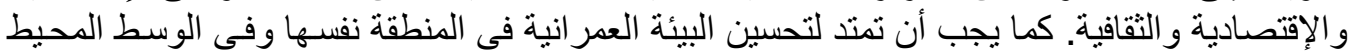

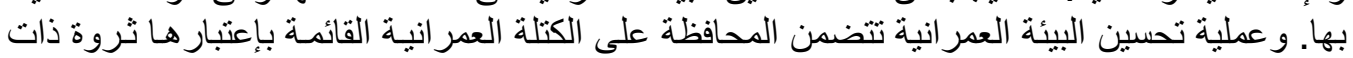

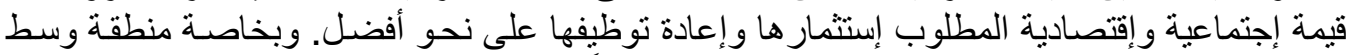

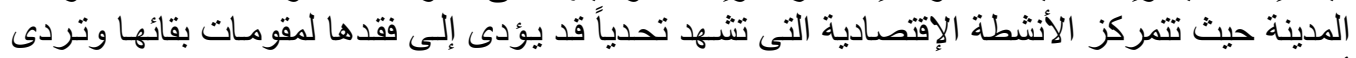
أوضاعها العمر انية.

\section{3- أبعاد مشكلة تذهور مراكز المدن القديمة والتراثية:

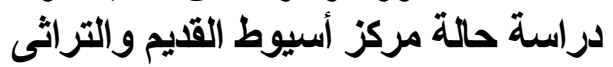

مركز مدينة أسيوط القديم يقع فى قلب المنطقة القديمة والتى تعرف في في مدينـة أسبوط بمنطقة

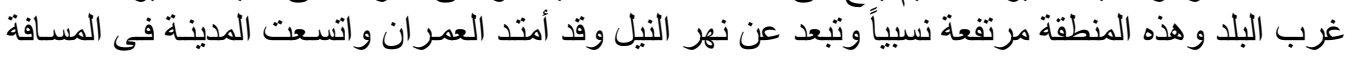

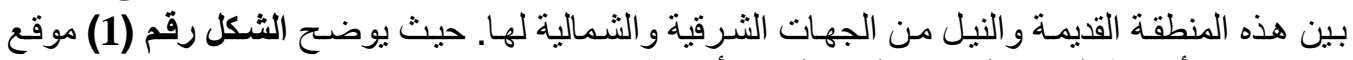

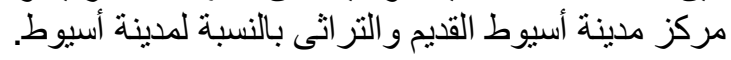

يتميز النسيج العمرانى للمركز القديم بوجود شار ع تجارى رئيسى وهو شار ع محمد محمود باشـا

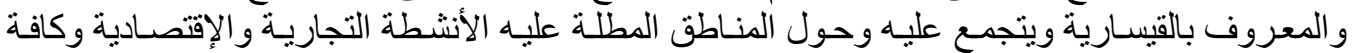

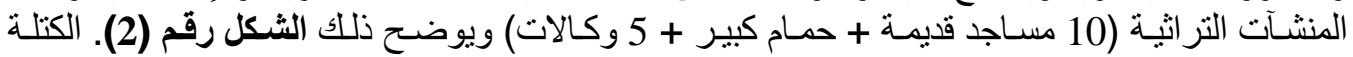

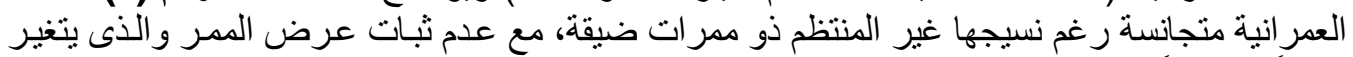

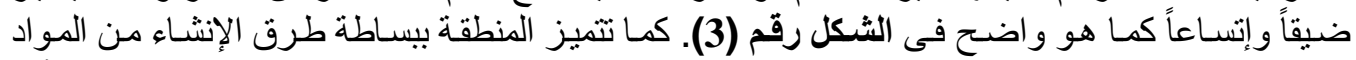

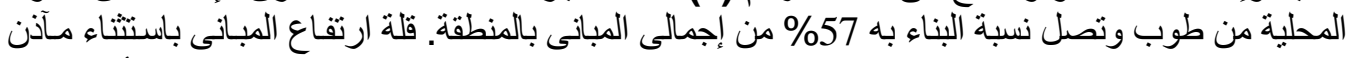

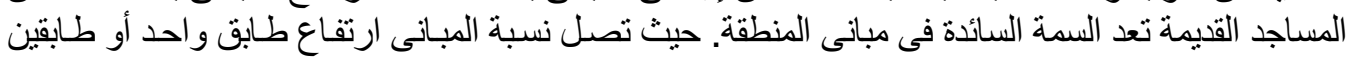
حو الى 80\% من إجمالى مبانى المنطقة [2]

ويمكن تحديد أهم أبعاد تدهور مر اكز المدن القديمة و التر اثيـة مثنل الحسادث فى حالة مركز أسيوط على النحو التالى:

\section{1-3 انحسار القيمة الوظيفية للمبانى أو عدم ملائمتها}

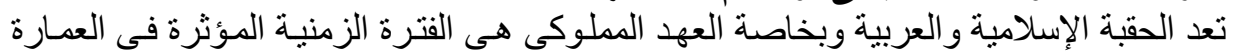

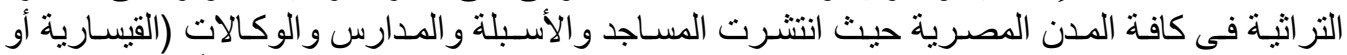

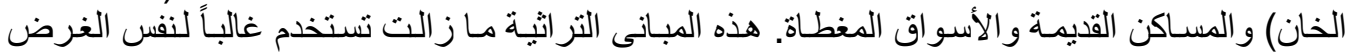

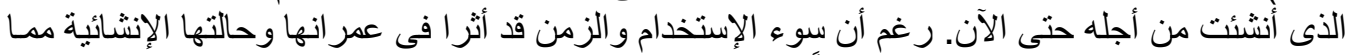

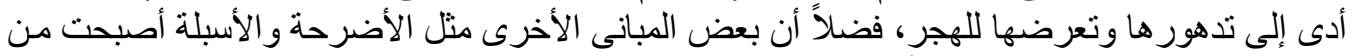

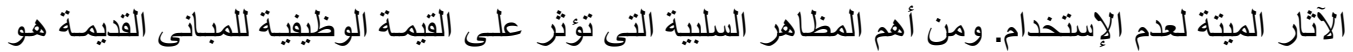

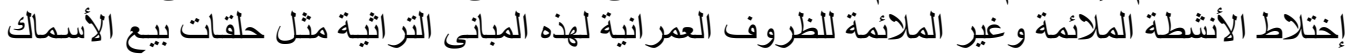

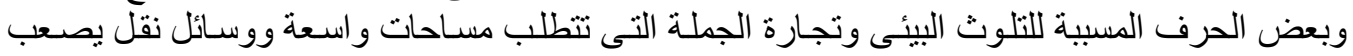
توفير ها فى منل هذه المناطق. 


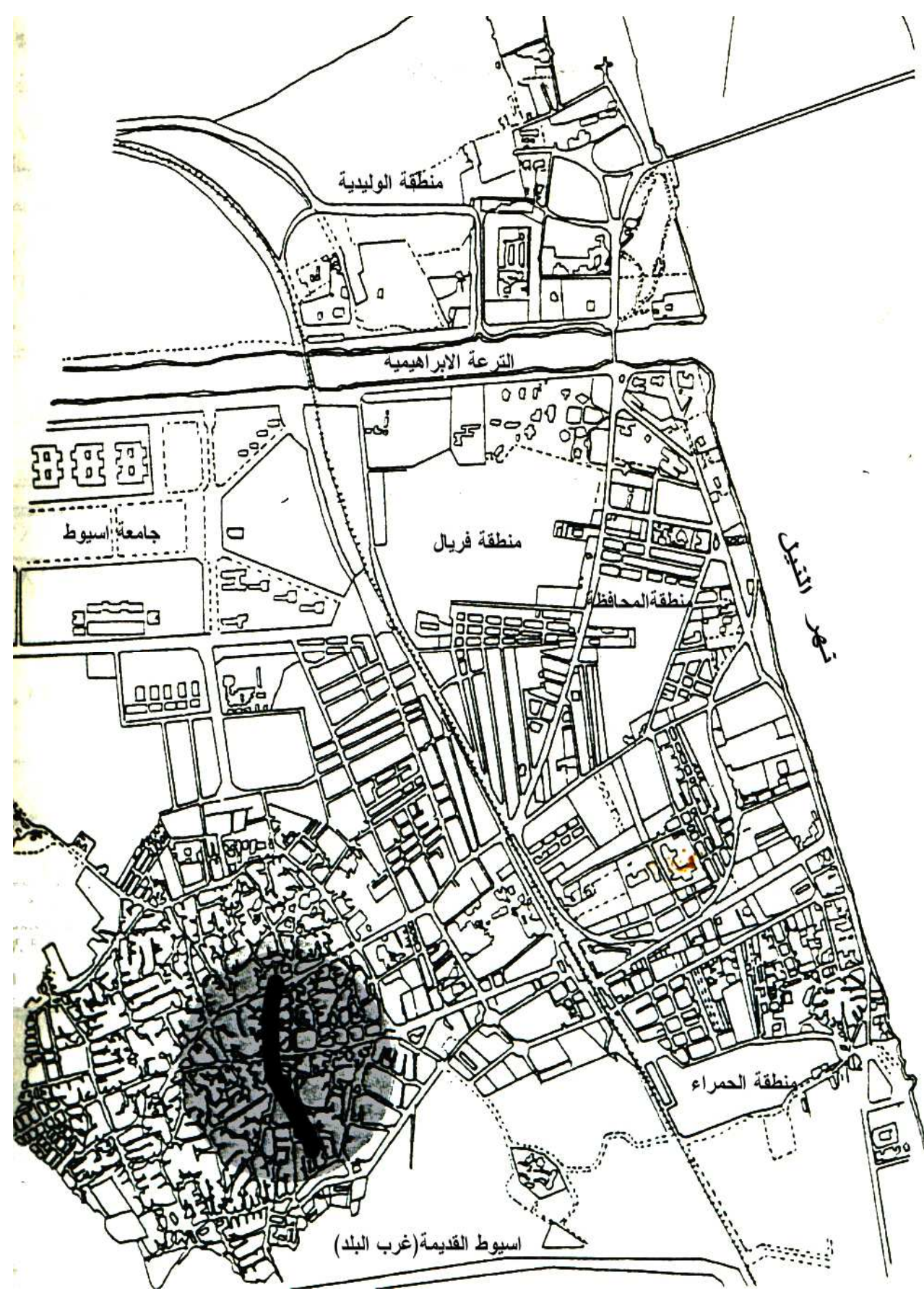

شكل رقم (1): خريطة توضح موقع مركز المدينة القيم و التر اثى لمدينة أسيوط 


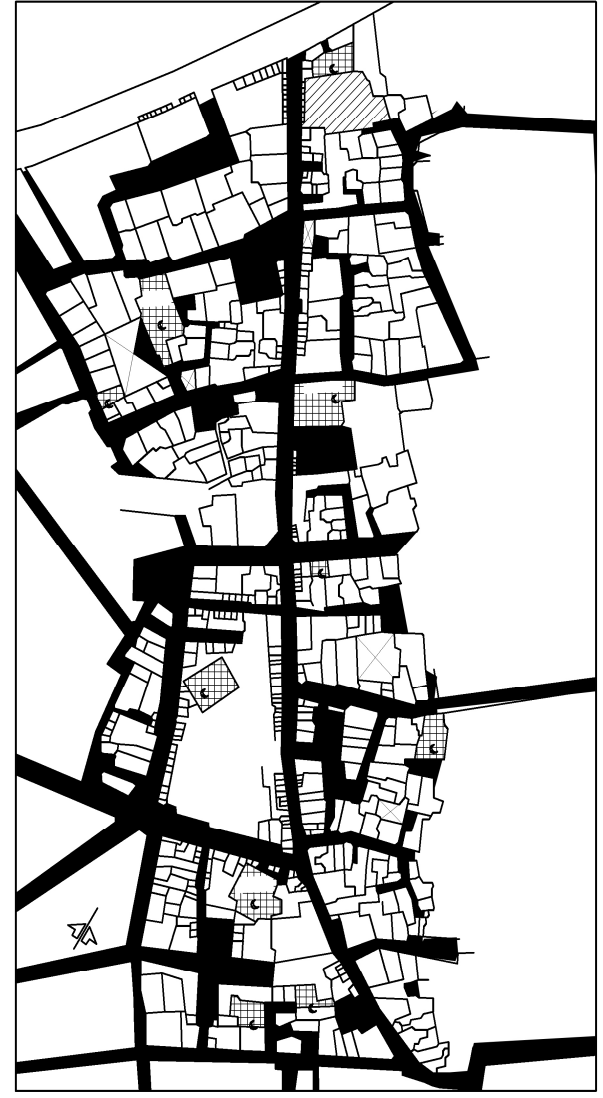

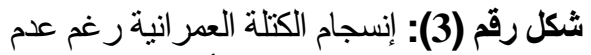
إنتظام النسيج العمر انى بمركز أسيوط القيلم.

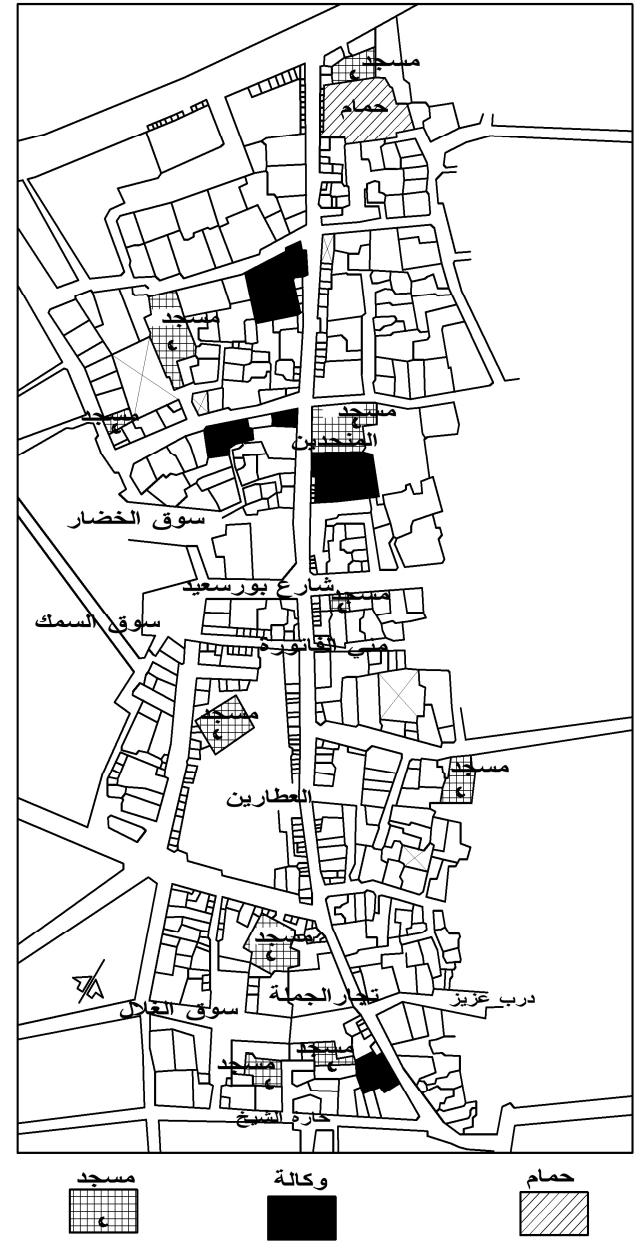

شكل رقم (2): خريطة لمركز مدينة أسيوط القيم توضح أهم الأنشطة التجارية والمبانى التراثية.

التطور ات الإقتصادية الحادثة التى تتمثل فى زيـادة الأنثطة التجاريـة وتعدد أنو اعها وأحجامها

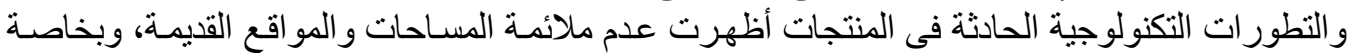

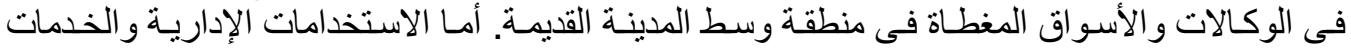

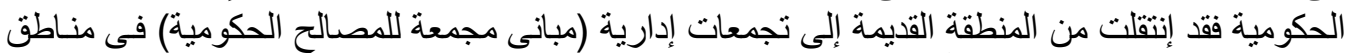

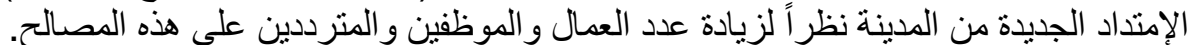

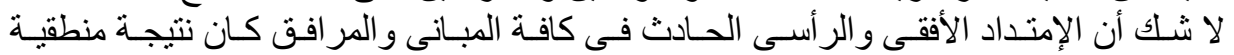

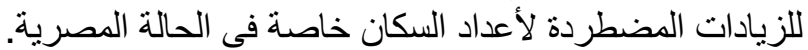

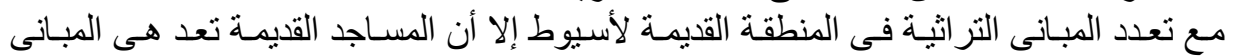

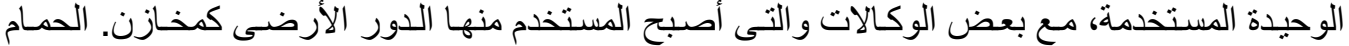
الأثرى بالمنطقة أغلق ولم تمند إليه يد العناية ويستخدم فى بعض الإلى الأحيان لتربية الأغنام. 


\section{2-3 تدهور الحالة الإنثائية للمبانى التراثية بمنطقة وسط المدينة القديمة}

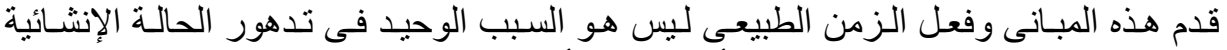

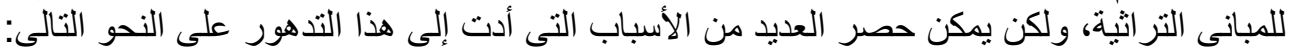

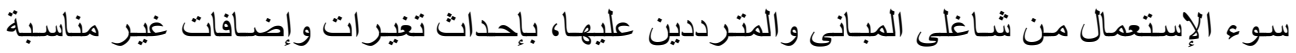
للمنشأ سو اء من ناحية الوظيفة أو الحالة الإلة الإنثائية.

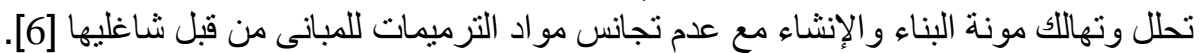

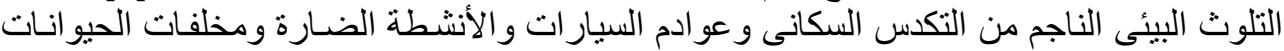
التى تجر العربات المستخدمة في النقل للبض النيائع.

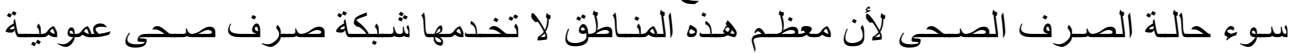

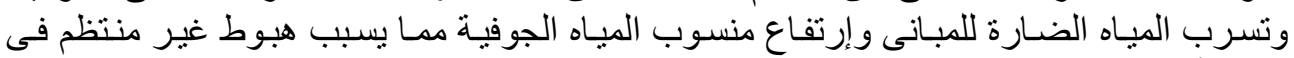
بعض أجز اء المبانى التر اثنية.

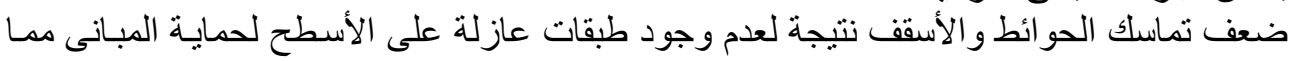

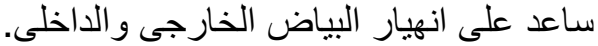

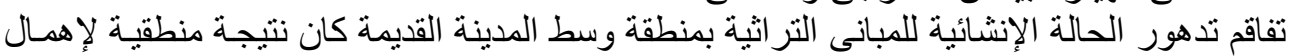

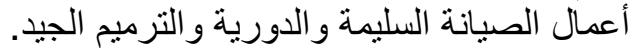

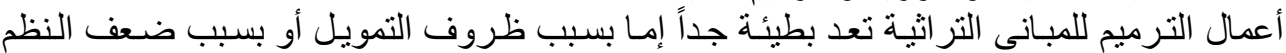

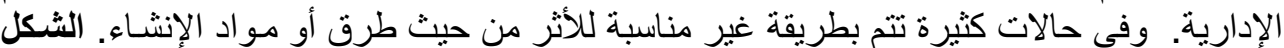

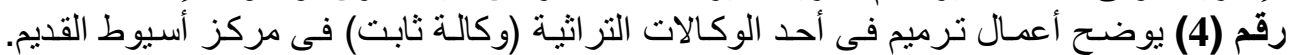

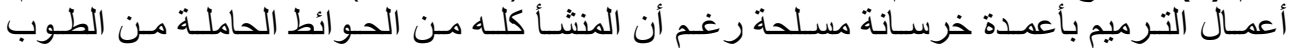

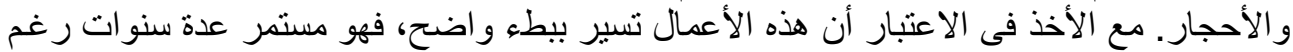
إمكانية إنجازه فى وقت محدود.

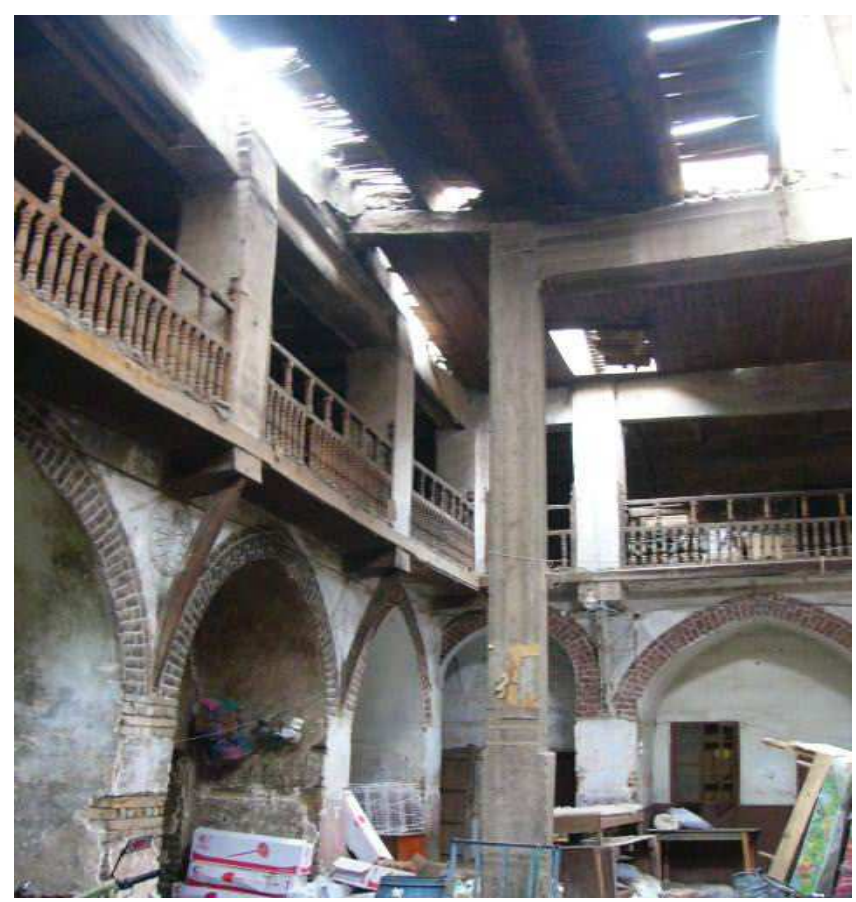

شكل رقم (4): أعمال الترميم بوكالة ثابت التراثية بمركز أسيوط القديم (القيسارية) بأعمدة من الخرسانة. 


\section{3-3 تعدد المشاكل العمرانية داخل منطقة وسط المدينة القديمة}

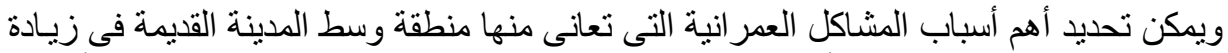

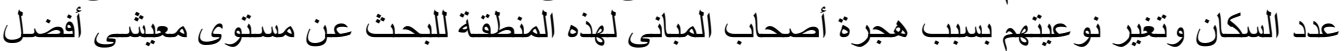

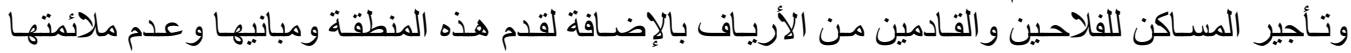

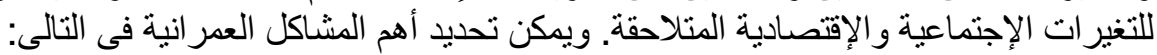

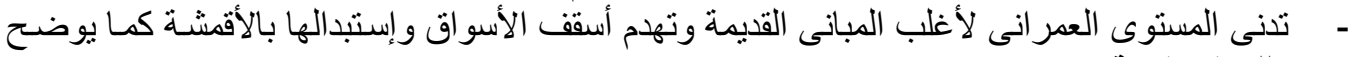

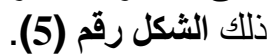

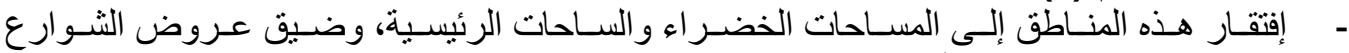

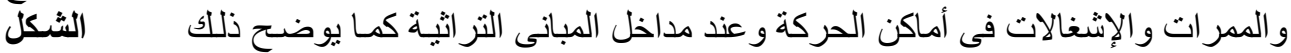

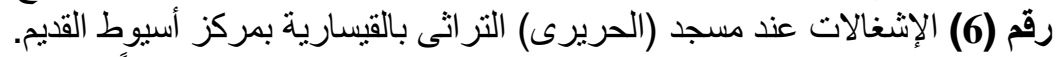

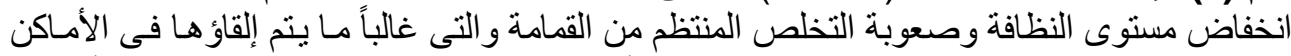

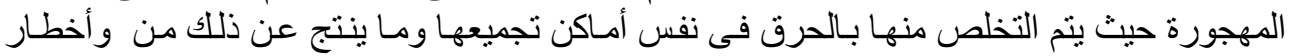
بيئية وصحية جسيمة. عدم توفر المر افق الأساسية من الصرف الصحى و المياه و الكهرباء والتليفونات فى أجز اء متعددة من

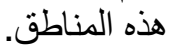

عدم كفاية الخدمات الأساسية الإجتماعية من مدارس ونو ادى ومر اكز شباب ومبانى صحية علاجية.

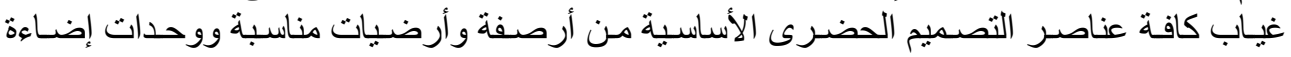

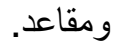
عدم التجانس الو اضح بين المبانى القديمة و المبانى الجديدة و التى تنتـأ دون أى إعتبار للقيم المعماريـة

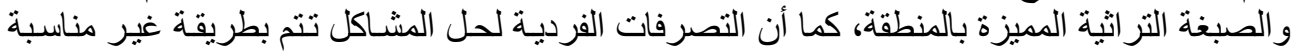
مثل تسقيف الممرات بأقمشة.

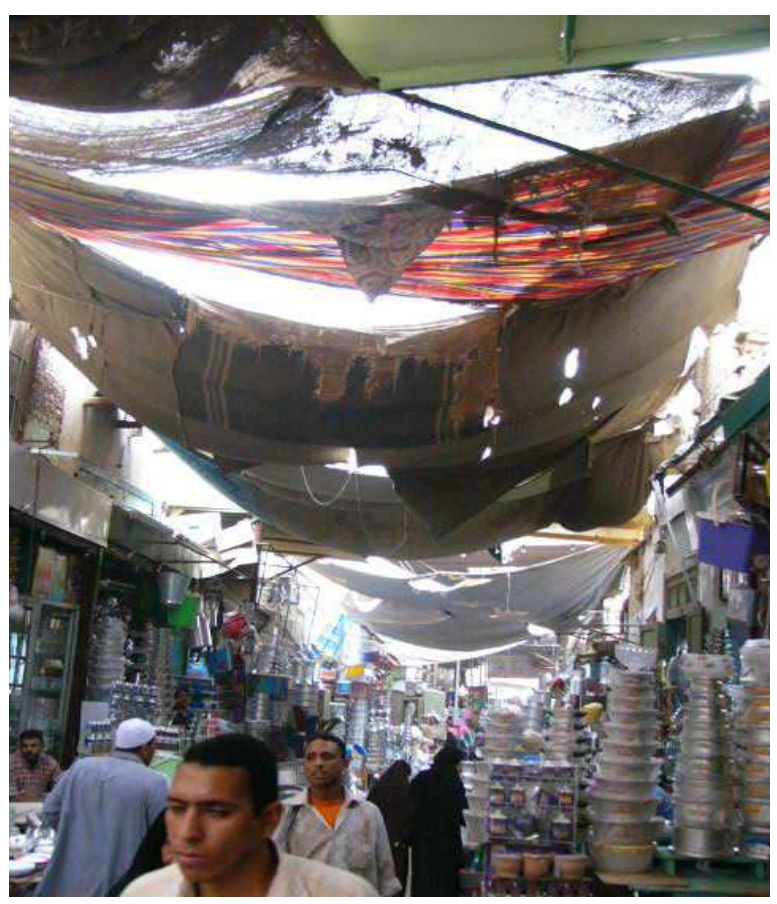

شكل رقم (5): الأسقف توضح تدنى المستوى العمر انى للمنطقة التجارية بمركز أسيوط القديم. 


\section{4-3 عدم ملائمة الوسط المحيط بالمنطقة القديمة والتراثية}

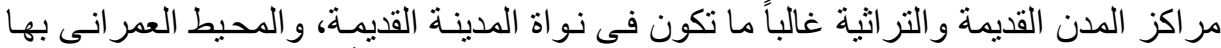

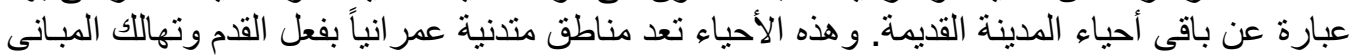

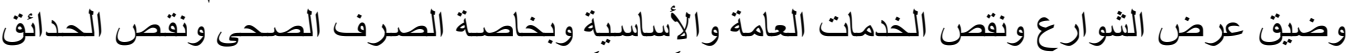

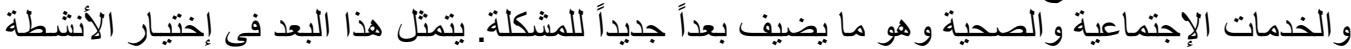

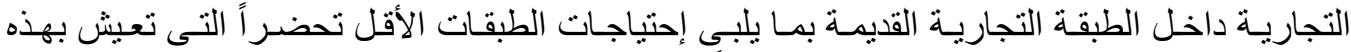

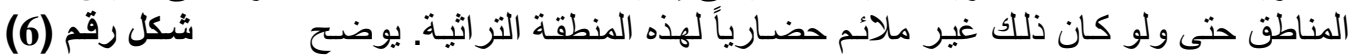
أنشطة غير مناسبة أسفل مبنى تر اثى (مسجد).

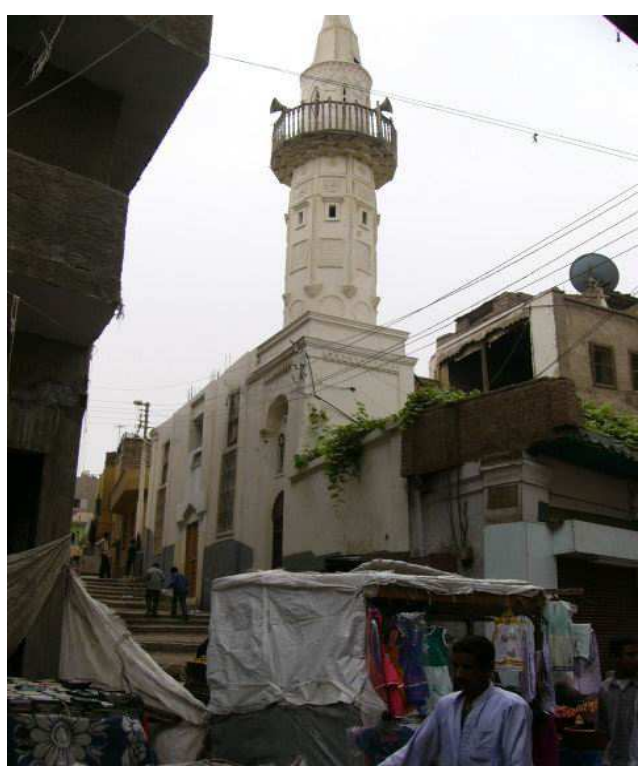

[ب] [إثغالات تجارية رديئة تحجب مدخل بالمجلة

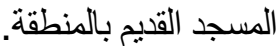

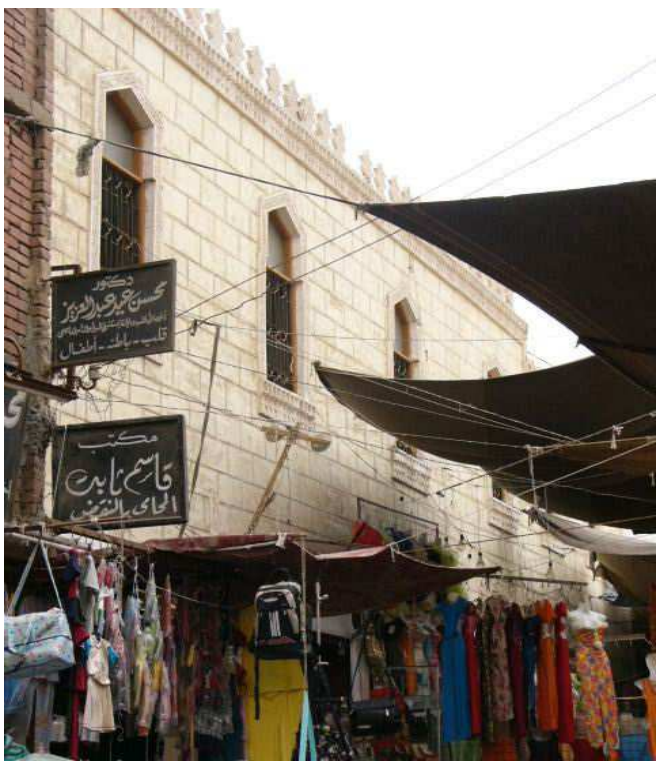

[ [ [ ] مسجد تراثى يشغل الدور الأرضى منه محلات تجارية لأنشطة غير ملاءمة للطابع الدينى للمكان.

شكل رقم (6): أنشطة غير مناسبة بمنطقة وسط المدينة القديمة والتر اثية بمدينة أسيوط بصعيد مصر.

\section{4- إتجاهات الحل لمشاكل مراكز المدن القديمة والتراثية: برنامج مقترح للتمية}

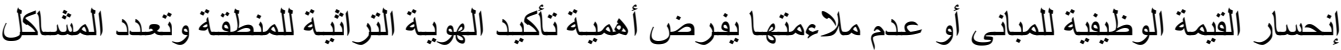

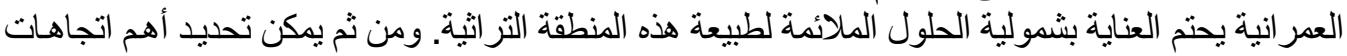

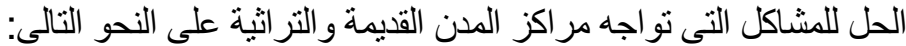

\section{1-4 تأكيد الهوية التراثية لمنطقة وسط المدينة القديمة}

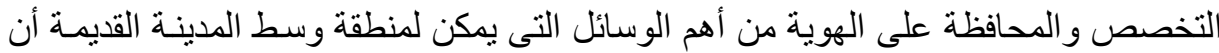

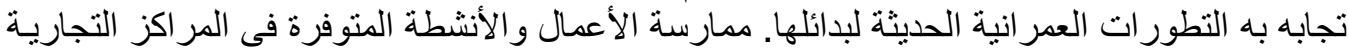

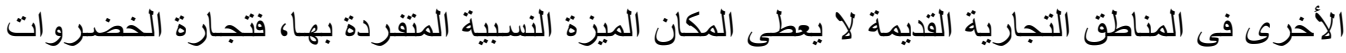

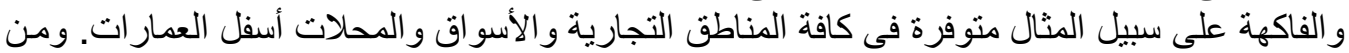

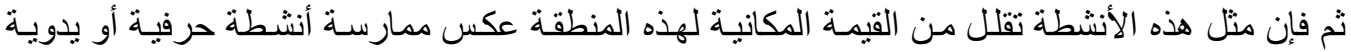


متميزة تعبر عن التراث الشعبى مثلاً، والذى بعطى المكان القديم التفرد المطلوب. شكل رقم (2) يوضح تقسيم المنطقة القديمة (القيسارية) بمدينة أسيوط لأجز اءئ حسب الأنشطة المختلفة، ونجد منها عدم ملائمة بعضها مثل حلقات السمك وتجارة الجملة.

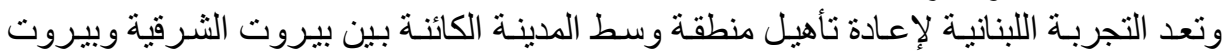

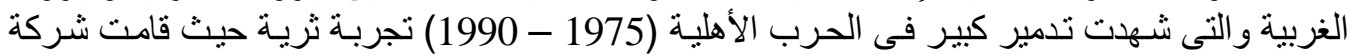

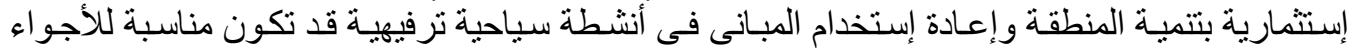

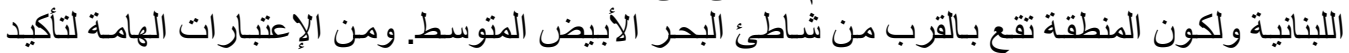

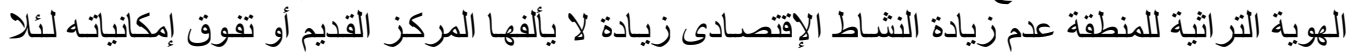

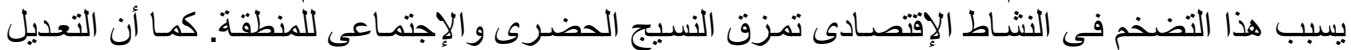

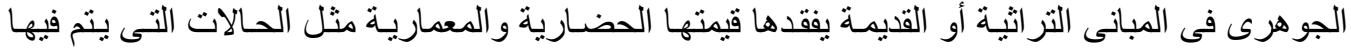

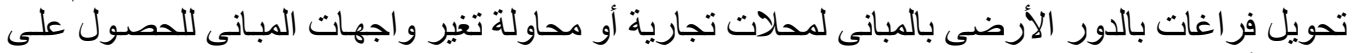
إضاءة أقوى و هكذا من الطرق المهدرة لقيمة المبانى و المنطقة التر اثية.

\section{2-4 تحقيق الملائمة البيئية والعمر انية للمنطقة}

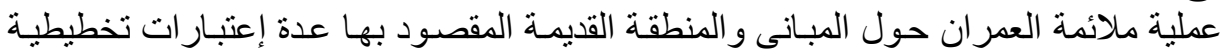

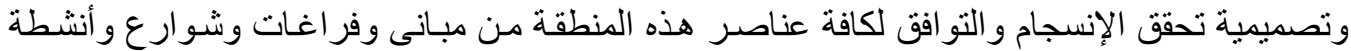

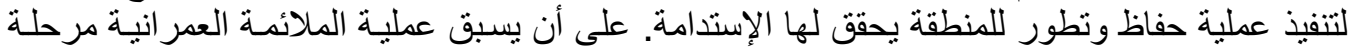

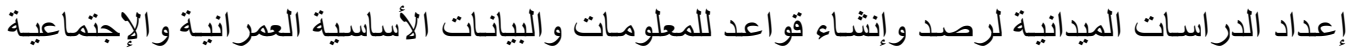

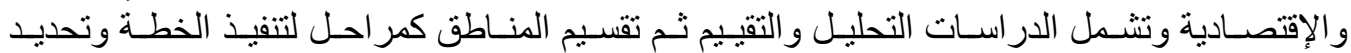
الأولويات فى كل مرحلة وبطريقة واضحة ثم إقتر اح آليات التنفيذ و التقويم. تفئ التهن

1-2-4 إعادة التخطيط العمرانى لحل مشكلة التزاحم المرورى:

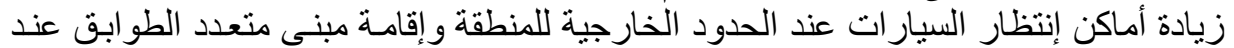

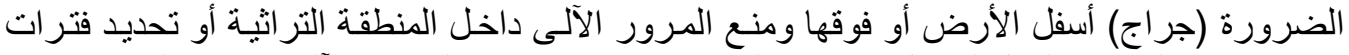

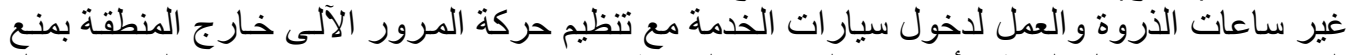

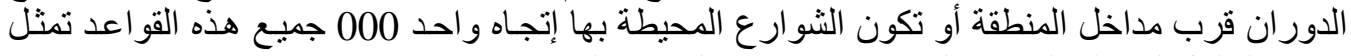
بعض الحلول لمشكلة التز احم المرورى مدرى عند هذه المنطقة الهامة.

2-2-4 الإدراك البصرى للمبانى التراثية بالمنطقة القديمة وملائمة المبانى خارجها:

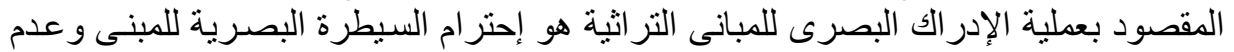

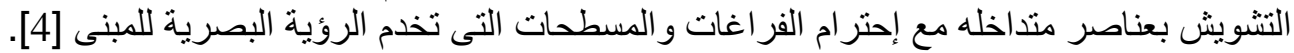

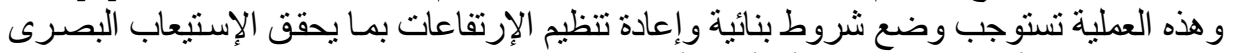

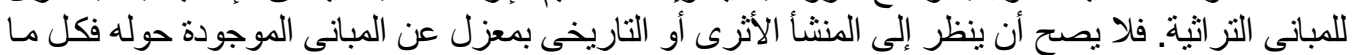

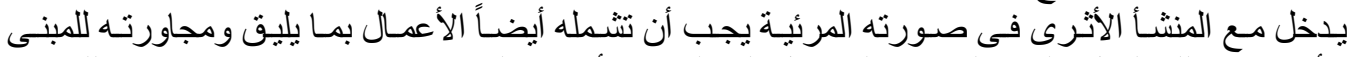

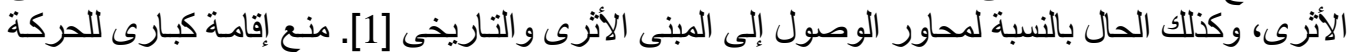

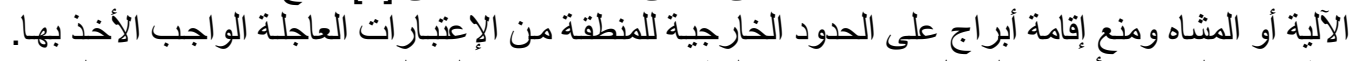

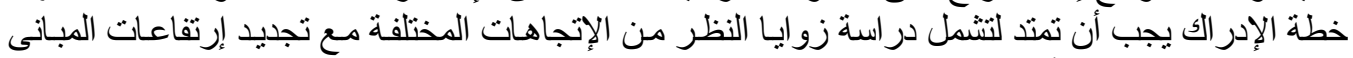

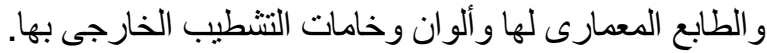

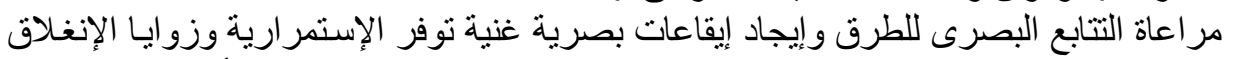

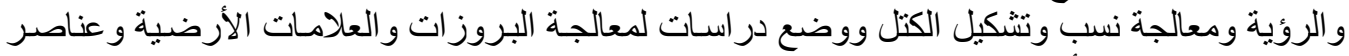
فرش الثو ارع من الأسس التصميمية لتنفيذ عملية الإدر الك البصرى المطلوبة. 


\section{3-4 توفير التمويل لتنفيذ عملية التنمية التيات}

أهمية إستثمار الإمكانيات والوفورات التيلة المتاحة في منطقة التتمية يعد أساسـاً هاماً لتوفير التمويل

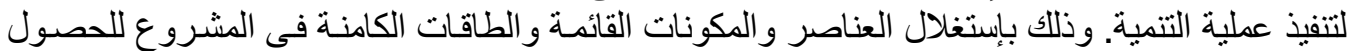

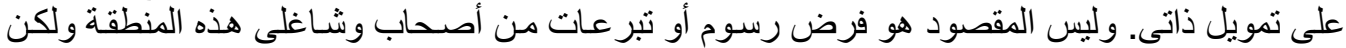

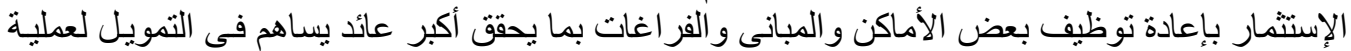

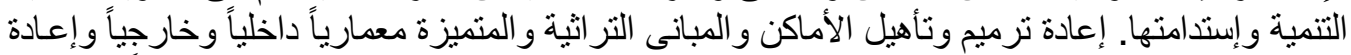

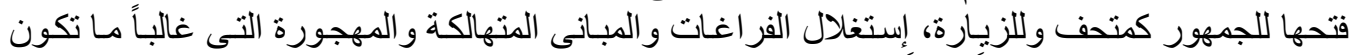

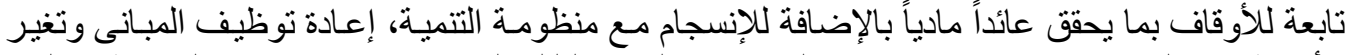

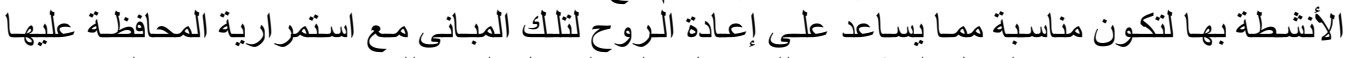

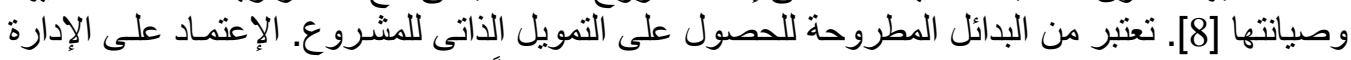

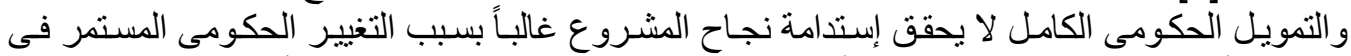

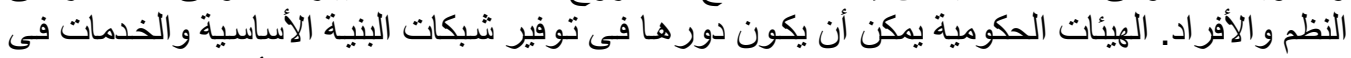

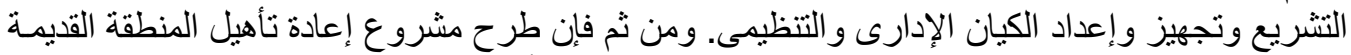

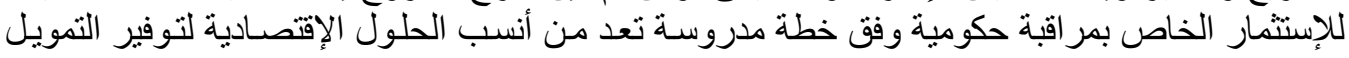

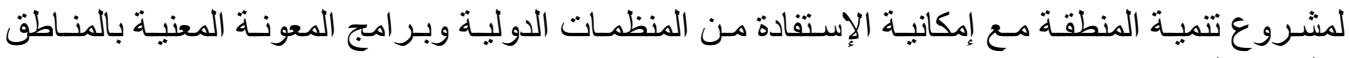

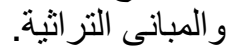

4-4 وضع برنامج لتحقيق التنمية المستدامة لمركز المدينة القديم والتراثى المئي

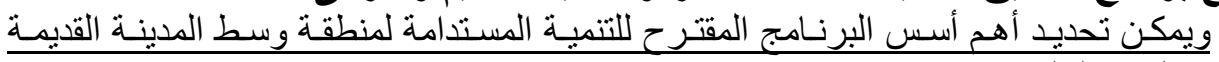

و والتزر اثية في البنود التنالية:

1-4-4 شمولية عملية التنمية لكافة الجوانب الإجتماعية والإقتصادية والعمرانية والبيئية:

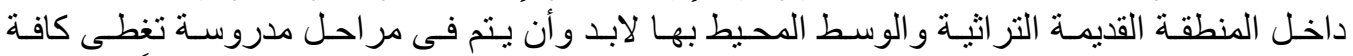

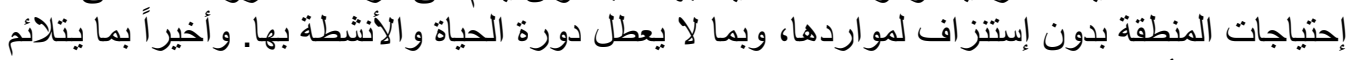
مع ظروف و أنظمة التمويل المتاحة.

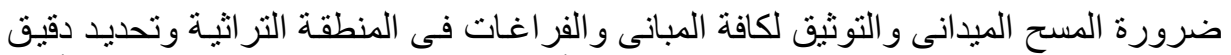

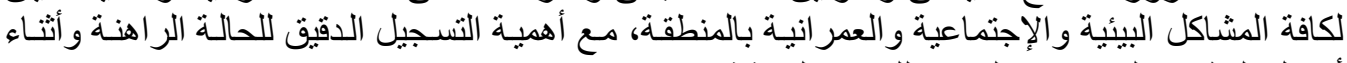

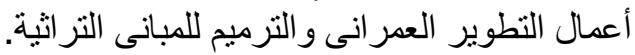

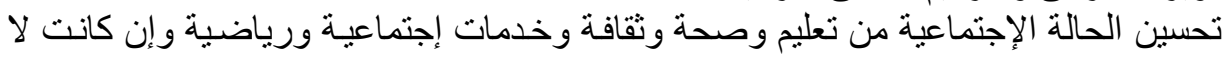

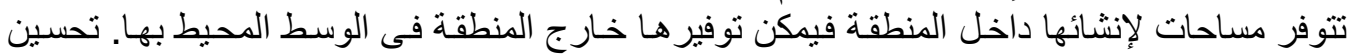

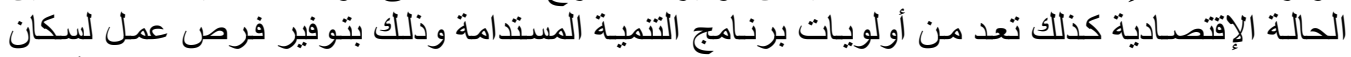

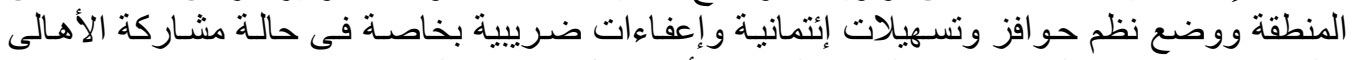

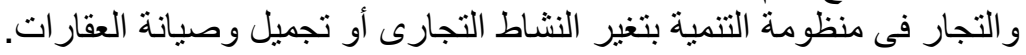

2-4-4 سرعة إنقاذ وترميم بعض المبانى التراثية بالمنطقة القديمة:

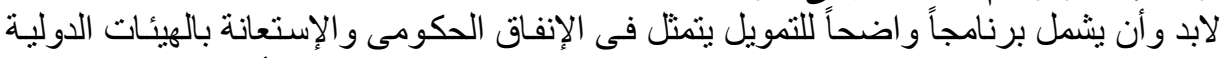

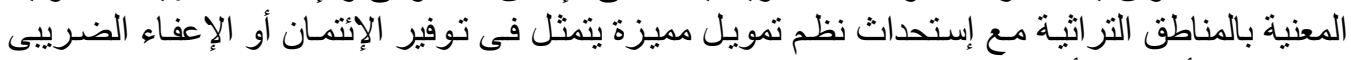

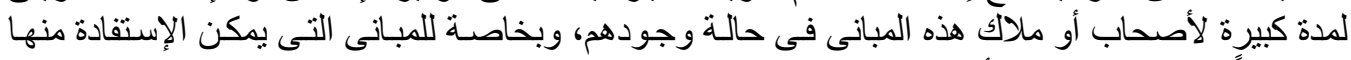

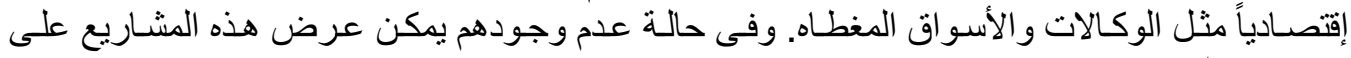




\section{3-4-4 تنفيذ المرحلة الأولى من برنامج التنمية المستدامة:}

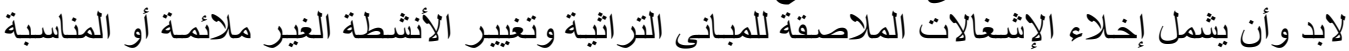
حول هذه المبانى بما يسمح بالإدر الك البصرى لها ونوفير البعد المكانى لرؤيتها بطريقة واضحة. لإنية.

\section{4-4-4 تنظيم حركة المرور للمشاه داخل الأسواق بالمنطقة:}

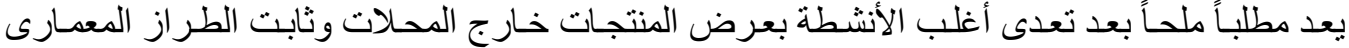

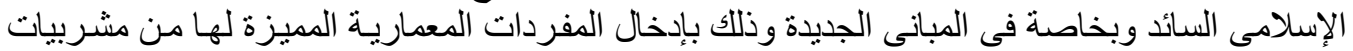

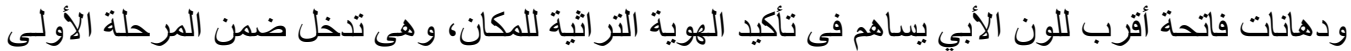
لبرنامج التنمية.

\section{5-4-4}

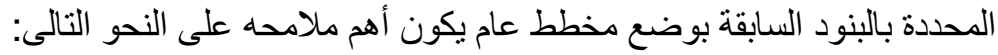

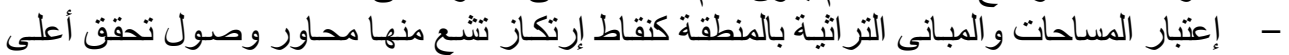

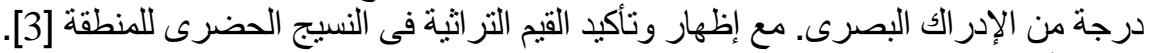

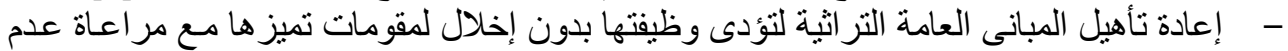

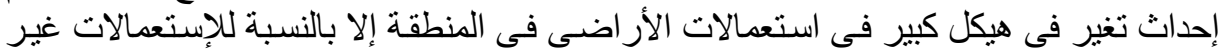

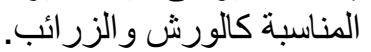

- - تحديد شروط بنائية وتخطيطية ملائمة لإظهار البعد التر اثى فى أى منشآت حديثة بالمنطقة.

\section{6-4-4 وضع برنامج توعية وتثقيف بالأولويات الحضارية والبيئية بالمنطقة:}

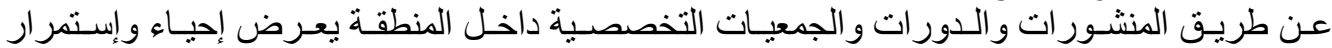

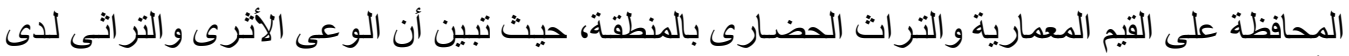

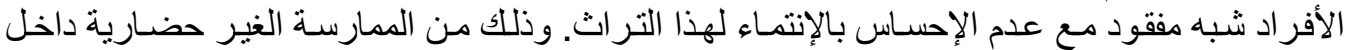

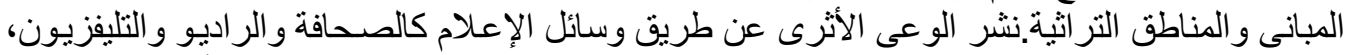

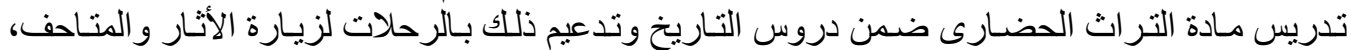

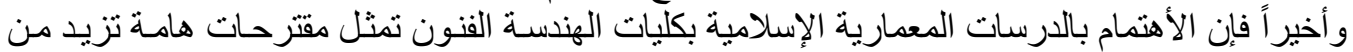

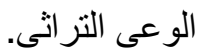

\section{5- الخلاصة والتوصيات}

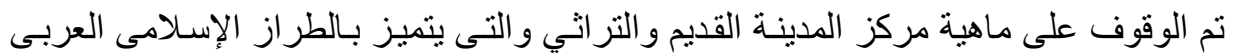

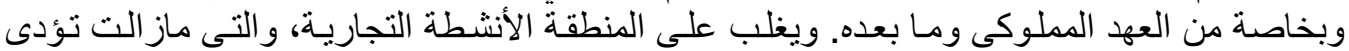

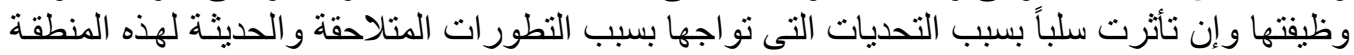

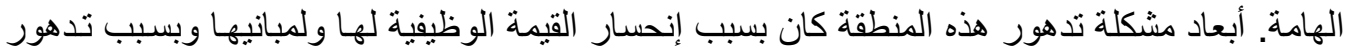

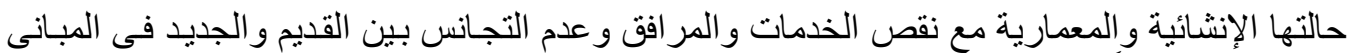

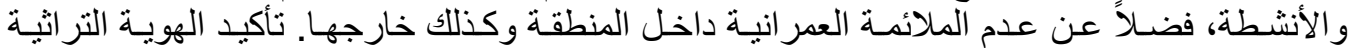

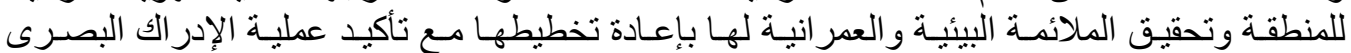

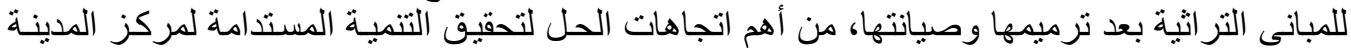

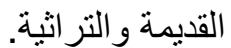

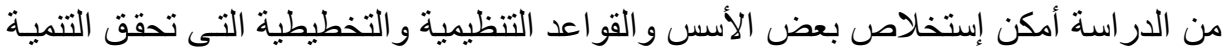

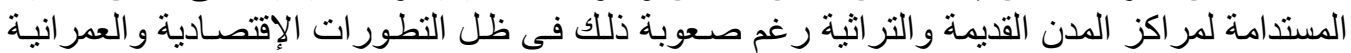

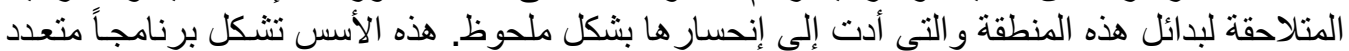

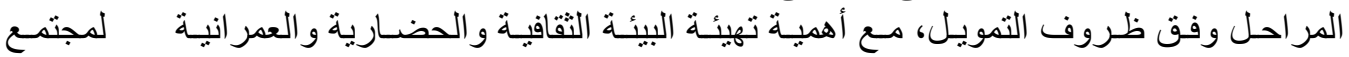


المنطقة القديمـة مـن الداخل وبالوسط المحيط بهـا لإجـر اء عمليـة التنميـة ويمكن تحديد أهم التوصيات

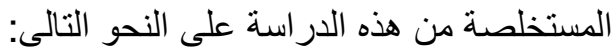

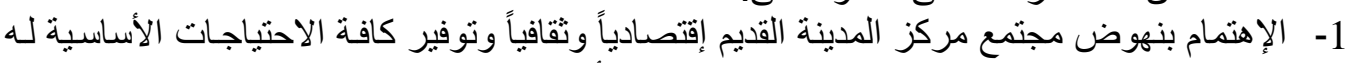

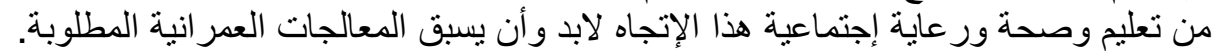

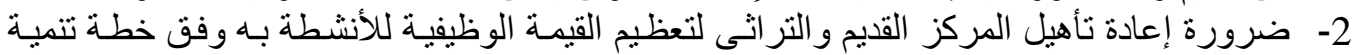
و اضحة المعالم و المر احل.

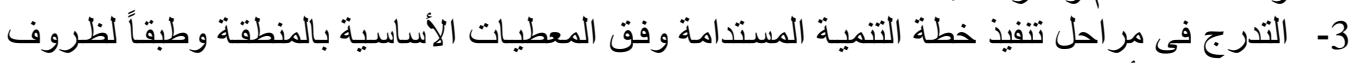

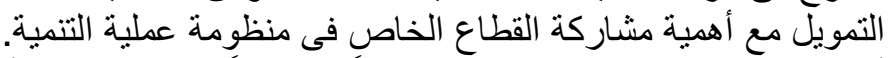

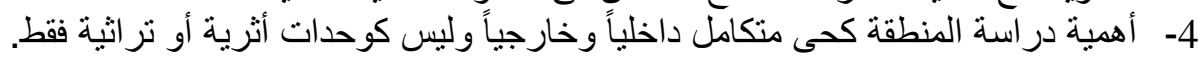

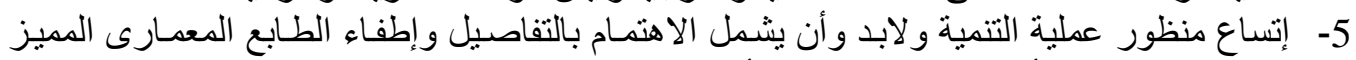

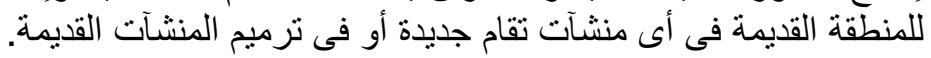

\section{6- المراجع}

[1] إير اهيم ، حازم محمد دكتور/1986- الإرتقاء بالمناطق التاريخية - ندوة الإرتقاء بالبيئة العمر انية

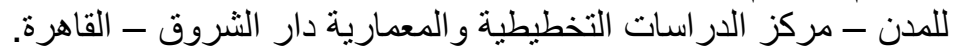

[2] أحمد ، كامل عبد الناصر دكتور / 1995 - أبعـاد وسياسـات الأرتقاء بالمنطقة القديمة ودر اسـة تطبيقية

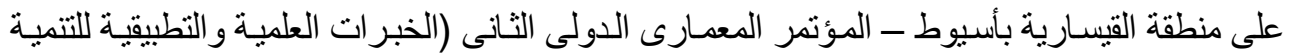

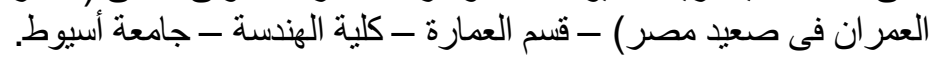

[3] الأرناؤوطى ، سحر محمود دكتور / 2001 - الإسكان و الثقافة و علاقتهم بالمحيط التاريخى للمدينة - مؤتمر جنوب لبنان - التحدى الحضرى فى زمن زمن التحرير 3 - 6 أبريل 2001 - جامعة بيروت العربية - مؤن لبنان

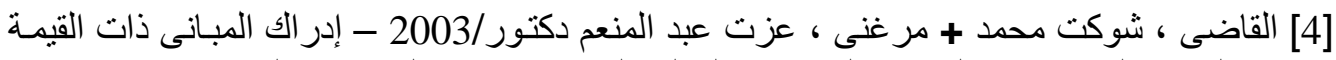

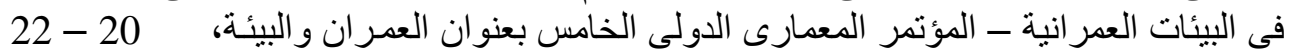

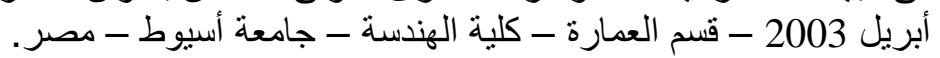

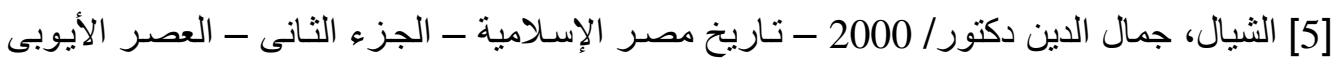

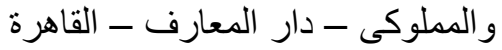
[6] جاب الله ، جاب الله على دكتور/2001 - مشروع ترميم وكالـة بازرعة ــ أثر رقم 398- وزارة

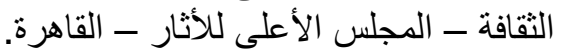

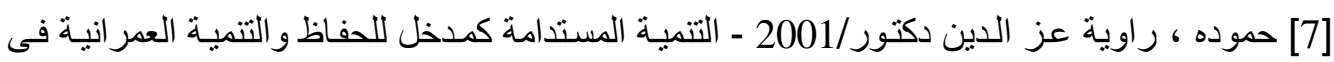

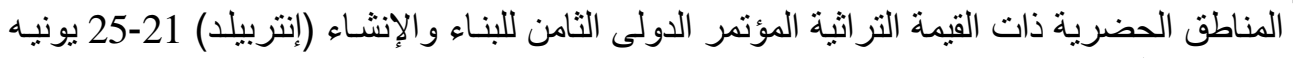

$$
2001
$$

[8] مر غنى ، عـزت عبد المـنعم دكتور / 2002- إعـادة توظيف المبـانى القديمـة كأحد أسـتر اتجيات

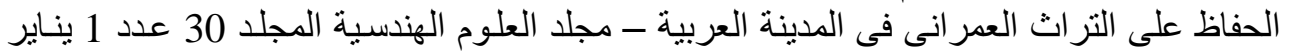

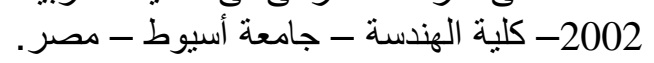

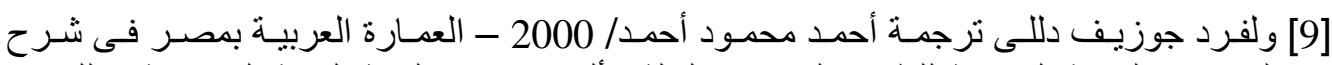
المميزات البنائية الرئيسية للطر از العربى، سلسلة الألف كتاب ـ الهيئة العامة المصرية الكئة للكتاب 